\title{
Allantofuranone, a new antifungal antibiotic from Allantophomopsis lycopodina IBWF58B-05A
}

\author{
Anja Schüffler ${ }^{1}$, Daniela Kautz ${ }^{1}$, Johannes C Liermann ${ }^{2}$, Till Opatz ${ }^{2}$ and Timm Anke ${ }^{3}$ \\ In a screening for new bioactive compounds, the extract of Allantophomopsis lycopodina strain IBWF58B-05A, an imperfect \\ ascomycete, was found to exhibit strong but rather selective antibiotic activity against Paecilomyces variotii. The bioactivity- \\ guided isolation yielded allantofuranone, a new and uncommon $\gamma$-lactone. This compound showed antifungal activity against \\ $P$. variotii and Penicillium species. This paper describes the isolation, structure elucidation and biological characteristics of \\ allantofuranone.
}

The Journal of Antibiotics (2009) 62, 119-121; doi:10.1038/ja.2008.21; published online 30 January 2009

Keywords: allantofuranone; Allantophomopsis; antifungal; $\gamma$-lactone

\begin{abstract}
INTRODUCTION
Fungi associated with plants have to adapt to environments differing greatly in their chemical composition and varying substantially during the host's development. They have to cope both with the plants defense and competing microorganisms and have therefore developed a rich and diverse secondary metabolism as part of their survival strategy. Allantophomopsis lycopodina is a plant pathogen responsible for leaf lesions on lingonberry, Vaccinium vitis-idaea ${ }^{1}$ and a fruit-rot pathogen (black rot) on cranberries, V. macrocarpon. ${ }^{2}$ To our knowledge, no secondary metabolites have been reported from this species. A closer look into the compounds produced during fermentations of our strain, however, revealed the presence of an antifungal antibiotic. In the following, we describe the production, isolation, structure elucidation and biological activities of allantofuranone (1), a new and unusual $\gamma$-lactone.
\end{abstract}

\section{RESULTS AND DISCUSSION}

Structure elucidation

The isolation of allantofuranone (1) was guided by its inhibitory activity against Paecilomyces variotii as described in the Experimental section. Allantofuranone had a nominal molecular weight of $324 \mathrm{Da}$ and an elemental composition determined by HR-MS of $\mathrm{C}_{19} \mathrm{H}_{16} \mathrm{O}_{5}$, requiring 12 unsaturations. The presence of two mono-substituted phenyl residues could be deduced by their characteristic pattern in the ${ }^{1}$ H-NMR spectrum. Their ortho protons were shifted downfield, and two of them showed a heteronuclear multiple bond correlation (HMBC) to a ketone carbonyl with a typical shift of 193.97 p.p.m. The carbonyl group itself exhibited intense correlations with two diastereotopic methylene protons forming an $\mathrm{AB}$ spin system. The neighboring quaternary center resonated at $\delta_{\mathrm{C}} 107.61$ and showed an HMBC correlation with a methoxy group at $\delta_{\mathrm{H}} 3.28$. The chemical shift of the quaternary carbon gave evidence for the presence of an acetal. The methylene protons showed a ${ }^{3} \mathrm{~J} \mathrm{C,H}$ correlation to a further quaternary carbon at 122.92 p.p.m., which is bound to the second phenyl residue. Only one of the two remaining carbon atoms showed a weak ${ }^{4} J$ correlation to one of the methylene protons. Their chemical shifts (167.46 and 140.19 p.p.m.) were in good agreement with those of C-2 and C-3 in a 3-hydroxyfuran-2 $(5 H)$-one ring. ${ }^{3}$ This hypothesis could later be confirmed by X-ray crystallography. Remarkably, allantofuranone crystallized in the centrosymmetric space group $P \overline{1}$, thus the natural product was racemic (Figures 1 and 2).

\section{Biological activities}

Up to $50 \mu \mathrm{g} \mathrm{ml}^{-1}$, no antibiotic activity was observed in the serial dilution assay against: Micrococcus luteus, Bacillus brevis, B. subtilis, Mycobacterium phlei, Pseudomonas aeruginosa, Athrobacter citreus, Corynebacterium insidiosum, Escherichia coli, Enterobacter dissolvens, Absidia glauca (+), A. glauca (-), Ascochyta pisi, Aspergillus ochraceus, Fusarium oxysporum, F. fujikuroi, Nematospora coryli, Zygorhynchus moelleri and Mucor miehei. Compound 1 exhibited antifungal activity against $P$. islandicum and $P$. notatum at $25 \mu \mathrm{g} \mathrm{ml}^{-1}$ and against P. variotii starting from $10 \mu \mathrm{g} \mathrm{ml}^{-1}$.

In the agar diffusion assay, the antifungal activity of 1 against $P$. notatum, $P$. islandicum and $P$. variotii was more pronounced (Table 1). Activity was observed against Magnaporthe grisea (15 $\mu$ g per disc) and $P$. lilacinus $(30 \mu \mathrm{g}$ per disc), whereas $P$. farinosa was not inhibited. Interestingly, $P$. lilacinus started forming reddish pigments beginning

${ }^{1}$ Department of Biotechnology, University of Kaiserslautern, Kaiserslautern, Germany; ${ }^{2}$ Institut für Organische Chemie, Department Chemie, Universität Hamburg, Hamburg, Germany and ${ }^{3}$ Institute of Biotechnology and Drug Research, Kaiserslautern, Germany 
at $5.0 \mu \mathrm{g}$ per disc of 1 . The germination of $P$. infestans and $M$. grisea spores was inhibited at an $\mathrm{IC}_{100}$ value of $50 \mu \mathrm{g} \mathrm{ml}^{-1}$. The spore germination of the other fungal species was not inhibited (up to $100 \mu \mathrm{g} \mathrm{ml}^{-1}$ ). No interference with respiration ( $P$. notatum and $P$. variotii) and no phytotoxic, cytotoxic and nematicidal effects were observed at concentrations of up to $100 \mu \mathrm{g} \mathrm{ml}^{-1}$.

Compounds such as xenofuranones A and B $(2,3),{ }^{3}$ butyrolactone II $(4)^{4}$ or WF-3681 $(5)^{5}$ show structural similarities to 1 . It was reported that they exhibited no antibacterial and only weak cytotoxic activity. This corresponds to our findings. The xenofuranones and WF-3681<smiles>CO[C@]1(CC(=O)c2ccccc2)OC(=O)C(O)=C1c1ccccc1</smiles>

1 Allantofuranone<smiles>COC(=O)[C@]1(Cc2ccc(O)cc2)OC(=O)C(O)=C1c1ccc(O)cc1</smiles>

4 Butyrolactone II<smiles>O=C1OC(Cc2ccccc2)C(c2ccccc2)=C1O</smiles>

2 Xenofuranone $A(R=M e)$ 3 Xenofuranone $B(R=H)$<smiles>O=C(O)CCC1OC(=O)C(O)=C1c1ccccc1</smiles>

5 WF 3681

Figure 1 Allantofuranone and related compounds.

showed no activity against yeasts, which also matches our results. Unfortunately, there was no information about their activity against filamentous fungi.

\section{EXPERIMENTAL SECTION}

\section{General}

Melting points were determined with a Dr Tottoli apparatus and are uncorrected. Optical rotations were measured with a Krüss P8000 polarimeter at $589 \mathrm{~nm}$. UV and IR spectra were measured with a Perkin-Elmer Lambda-16 spectrophotometer and a Bruker IFS48 FTIR spectrometer, respectively. NMR spectra were recorded with a Bruker Avance-II or with a Bruker DRX-500 spectrometer. The spectra were measured in $\mathrm{CDCl}_{3}$ and the chemical shifts were referenced to the residual solvent signal $\left(\mathrm{CDCl}_{3}: \delta_{\mathrm{H}}=7.26\right.$ p.p.m. and $\delta_{\mathrm{C}}=77.16$ p.p.m.). ${ }^{6}$ APCIMS spectra were measured with a Hewlett Packard MSD1100. FD-MS spectra were recorded on a Finnigan MAT 95 spectrometer. ESI-HRMS spectra were recorded on a MicroMass/Waters Q-TOF Ultra 3 spectrometer equipped with a LockSpray interface using $\mathrm{NaI} / \mathrm{CsI}$ or trialkylamines as external reference.

Table 1 Antifungal activity of allantofuranone (1) in the agar plate diffusion assay

\begin{tabular}{llllllllllll}
\hline & \multicolumn{1}{c}{ Diameter inhibition zone $(\mathrm{mm}) \mu g$ per disc ${ }^{\mathrm{a}}$} \\
\cline { 2 - 11 } & 0.5 & 1 & 2.5 & 5.0 & 10 & 15 & 20 & 30 & 40 \\
\hline Penicillium notatum & - & - & $10 \mathrm{i}$ & $13 \mathrm{i}$ & $17 \mathrm{i}$ & $20 \mathrm{i}$ & $21 \mathrm{i}$ & $22 \mathrm{i}$ & $24 \mathrm{i}$ \\
P. islandicum & - & - & - & $12 \mathrm{i}$ & $23 \mathrm{i}$ & $27 \mathrm{~d}$ & $29 \mathrm{~d}$ & $35 \mathrm{~d}$ & $44 \mathrm{~d}$ \\
Paecilomyces variotii & - & $12 \mathrm{i}$ & $27 \mathrm{~d}$ & $29 \mathrm{~d}$ & $38 \mathrm{~d}$ & $42 \mathrm{~d}$ & $45 \mathrm{~d}$ & $47 \mathrm{~d}$ & $47 \mathrm{~d}$ \\
P. lilacinus & - & - & - & - & - & - & - & $12 \mathrm{i}$ & $14 \mathrm{i}$ \\
Magnaporthe grisea & - & - & - & - & - & $12 \mathrm{i}$ & $15 \mathrm{i}$ & $20 \mathrm{i}$ & $23 \mathrm{i}$ \\
\hline
\end{tabular}

Abbreviations: $d$, inhibition zone diffuse; i, inhibition zone incomplete. aDiameter $6 \mathrm{~mm}$.

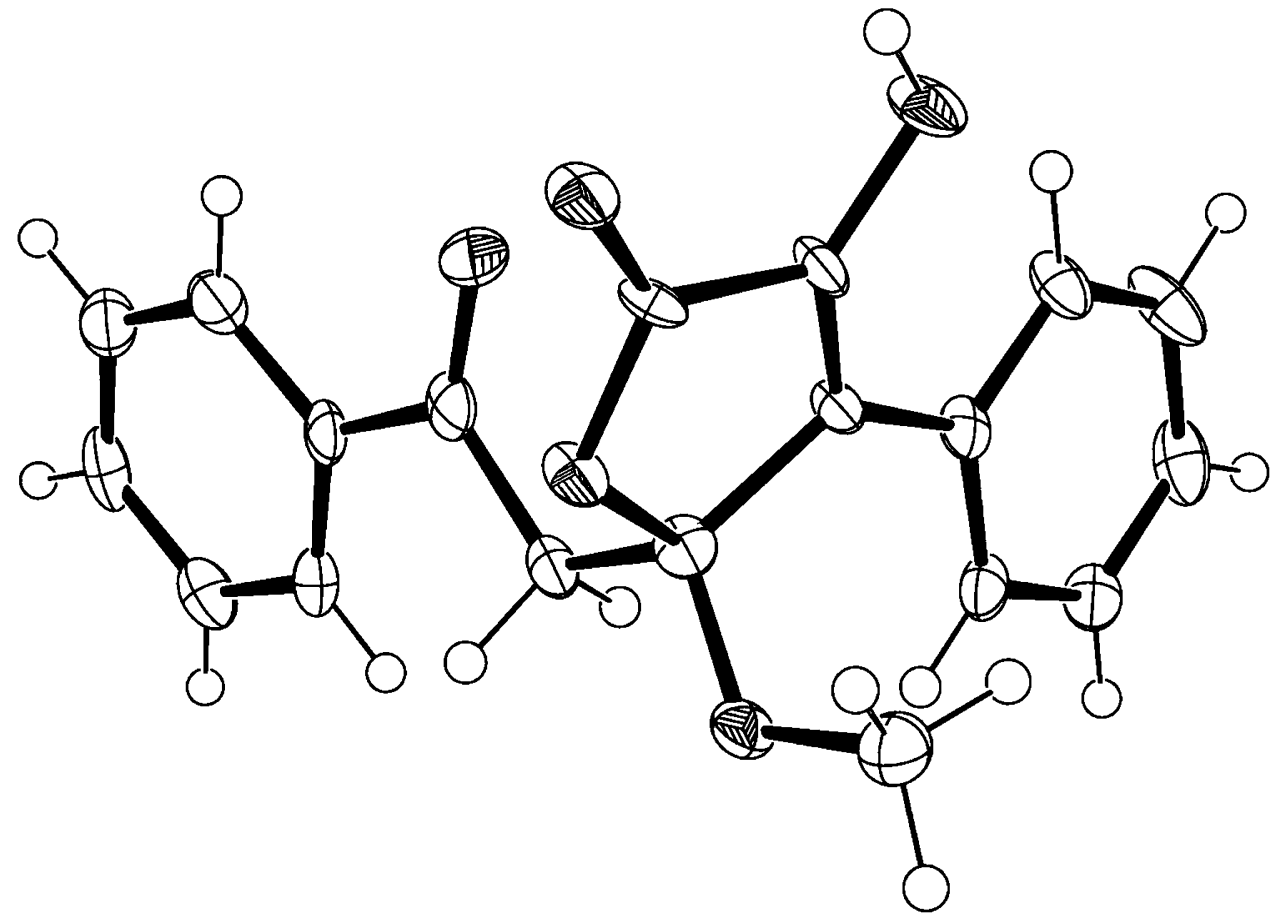

Figure 2 Crystal structure of 1 (ORTEP, ellipsoids drawn at 50\% probability). 


\section{Producing organism}

The filamentous ascomycete IBWF58B-05A was isolated from a strongly rotten piece of wood from a deciduous tree collected in France. It was identified by microscopy and sequencing of its internal transcribed spacer (ITS). The ITS sequence shows homologies of $99.8 \%$ to A. lycopodina IFO 32908 (GenBank accession no. AB041243). The microscopic characteristics fit the description by Carris. ${ }^{7}$ The spores are inequilateral/light lunate shaped, $2.5-3 \mu \mathrm{m} \times 10-13 \mu \mathrm{m}$ and are produced in conidiomata (diameter $100-300 \mu \mathrm{m}$ in YMG agar culture). The agar culture is dark grey-brown to black. Strain IBWF58B-05A has been deposited in the culture collection of the Institute of Biotechnology and Drug Research (IBWF e.V.), Kaiserslautern, Germany. For maintenance, the fungus was grown on agar slants on YMG agar (yeast extract $4.0 \mathrm{gl}^{-1}$, malt extract $10 \mathrm{gl}^{-1}$, glucose $10 \mathrm{gl}^{-1}$, the $\mathrm{pH}$ value was adjusted to 5.5 before autoclaving). Solid media contained $2.0 \%$ of agar.

\section{Fermentation and isolation}

The fungus was grown in YMG medium in a 20-1 fermenter (Biolafitte C6) at $22-24{ }^{\circ} \mathrm{C}$ with agitation (130 r.p.m.) and aeration $\left(31 \mathrm{~min}^{-1}\right)$. For inoculation, a well-grown shake culture $(500 \mathrm{ml})$ in the same medium was used. When the carbon source was depleted after 7 days, the fermentation was stopped. The culture fluid (16.5l) was separated from the mycelia by filtration and extracted twice with an equal volume of EtOAc. After evaporation of the solvent, the oily crude extract $(4.5 \mathrm{~g})$ was applied onto a column with silica gel (Merck 60, $0.063-0.2 \mathrm{~mm}, 150 \mathrm{~g}$ ). Elution with cyclohexane/EtOAc (3:1) yielded $693 \mathrm{mg}$ of an intermediate product. Pure 1 was obtained by preparative HPLC (Merck, Lichrosorb RP 18, $7 \mu \mathrm{m}$, column $250 \mathrm{~mm} \times 25 \mathrm{~mm}$ ) with a MeCN/ $\mathrm{H}_{2} \mathrm{O}$ gradient $\left(50-62 \% \mathrm{MeCN}\right.$ in $12 \mathrm{~min}$, flow: $20 \mathrm{ml} \mathrm{min}^{-1}$; yield: $191.3 \mathrm{mg}$ (Rt 10.5-12.0 min).

\section{Allantofuranone (1)}

Yellow crystals, m.p. $147-149^{\circ} \mathrm{C}$; no significant optical rotation was detected; $\mathrm{UV} \lambda_{\max }^{\mathrm{MeOH}}(\mathrm{nm})(\log \varepsilon) 227$ (4.08), 246 (4.21), 289 (4.26); $\lambda_{\mathrm{mun}}^{\mathrm{MeOH}}(\mathrm{nm})(\log$ $\varepsilon)=219$ (4.04), 231 (4.06), 262 (4.03); IR $v_{\max }(\mathrm{KBr})\left(\mathrm{cm}^{-1}\right) 3304,1755,1695$, 1394, 1304, 1216, 1177, 1152, 1122, 989, 766, 689; FD-MS m/z 324.1 (M) ${ }^{+}$, $648.6(2 \mathrm{M})^{+}$; ESI-HRMS $\mathrm{m} / z 347.0891$ (calcd for $\mathrm{C}_{19} \mathrm{H}_{16} \mathrm{O}_{5}+\mathrm{Na}^{+} 347.0890$ ). ${ }^{1} \mathrm{H}-$ and ${ }^{13} \mathrm{C}-\mathrm{NMR}$ data are presented in Table 2.

\section{X-ray crystallographic data of 1}

Crystals of 1 were grown by slow evaporation of a methanolic solution of 1. Data were obtained at $100 \mathrm{~K}$ on a Bruker APEX diffractometer with graphite-monochromated Mo- $\mathrm{K}_{\alpha}$ radiation. Formula $\mathrm{C}_{19} \mathrm{H}_{16} \mathrm{O}_{5}$, crystal size $0.02 \times 0.10 \times 0.38 \mathrm{~mm}^{3}$, triclinic, space group $P \overline{1}, a=8.779(4) \AA, b=9.672(4) \AA$, $c=10.765(5) \AA, \alpha=75.886(8)^{\circ}, \quad \beta=76.808(7)^{\circ}, \quad \gamma=79.356(7)^{\circ}, V=816.4(6) \AA^{3}$, $Z=2, D=1.319 \mathrm{~g} \mathrm{~cm}^{-3}, R=0.0638, R_{\mathrm{w}}=0.1417$. CCDC-717550 contains the supplementary crystallographic data for this paper. These data can be obtained free of charge at www.ccdc.cam.ac.uk/conts/retrieving.html (or from the Cambridge Crystallographic Data Centre, 12 Union Road, Cambridge CB2 1EZ, UK; Fax: +44-1223/336-033; E-mail: deposit@ccdc.cam.ac.uk).

\section{Biological assays}

Antimicrobial activities against bacteria and fungi were determined in the agar plate diffusion or serial dilution assay as described previously. ${ }^{8}$ Cytotoxicity was assayed as described previously. ${ }^{9}$ The cell lines Jurkat (ATCC TIB 152), Colo320 (DSMZ ACC 144) and L-1210 (DSMZ ACC 123) were grown in RPMI 1640 medium (Invitrogen, Karlsruhe, Germany). Neuro-2A (DSMZ ACC 148) and SH-SY5Y (DSMZ ACC209) were grown in DMEM medium (Invitrogen). All media were supplemented with $10 \%$ heat-inactivated fetal calf serum (Invitrogen), $65 \mu \mathrm{g} \mathrm{ml}^{-1}$ of penicillin $\mathrm{G}$ and $100 \mu \mathrm{g} \mathrm{ml}^{-1}$ of streptomycin sulfate. The viability was measured photometrically with XTT (suspension cell lines) or with Giemsa staining (monolayer cells). The influence of $\mathbf{1}$ on the oxygen uptake by $P$. variotii and Penicillium notatum was tested as described previously. ${ }^{10}$ Phytotoxicity was tested with Setaria italica and Lepidium sativum. ${ }^{11}$ The spore germination was tested with $M$. grisea as described
Table $2{ }^{1} \mathrm{H}-(400 \mathrm{MHz})$ and ${ }^{13} \mathrm{C}$-NMR $(101 \mathrm{MHz})$ of 1 in $\mathrm{CDCl}_{3}$

\begin{tabular}{lcr}
\hline Position & $\delta_{H}$ & $\delta_{C}$ \\
\hline 2 & - & $167.46(\mathrm{~s})$ \\
3 & - & $140.19(\mathrm{~s})$ \\
4 & - & $122.92(\mathrm{~s})$ \\
5 & - & $107.61(\mathrm{~s})$ \\
6 & $3.90,(\mathrm{~d}, \mathrm{~J}=16.5 \mathrm{~Hz})$ & $43.97(\mathrm{~d})$ \\
& $3.67,(\mathrm{~d}, \mathrm{~J}=16.5 \mathrm{~Hz})$ & \\
7 & - & $193.97(\mathrm{~s})$ \\
8 & - & $136.99(\mathrm{~s})$ \\
$9 / 13$ & $7.83(\mathrm{~m})$ & $128.33(\mathrm{~d})$ \\
$10 / 12$ & $7.40(\mathrm{~m})$ & $128.71(\mathrm{~d})$ \\
11 & $7.52(\mathrm{~m})$ & $133.54(\mathrm{~d})$ \\
$1^{\prime}$ & - & $129.17(\mathrm{~s})$ \\
$2^{\prime} / 6^{\prime}$ & $7.89(\mathrm{~m})$ & $127.72(\mathrm{~d})$ \\
$3^{\prime} / 5^{\prime}$ & $7.45(\mathrm{~m})$ & $129.20(\mathrm{~d})$ \\
$4^{\prime}$ & $7.37(\mathrm{~m})$ & $129.45(\mathrm{~d})$ \\
$5-\mathrm{OCH}_{3}$ & $3.28(\mathrm{~s})$ & $50.16(\mathrm{q})$ \\
\hline
\end{tabular}

previously. ${ }^{12}$ This method was adapted for the spore germination assay with Phytophthora infestans, Botrytis cinerea and Fusarium graminearum. The nematicidal activity was tested with Meloidogyne incognita and Caenorhabditis elegans as described earlier. ${ }^{13}$

\section{ACKNOWLEDGEMENTS}

Strain IBWF58B-05A was kindly provided by Professor H Anke, IBWF. We thank H Kolshorn (University of Mainz) for NMR spectroscopy, I Nevoigt (University of Hamburg) for the X-ray crystallographic analysis and N Hanold (University of Mainz) for mass spectrometry.

1 Putnam, M. L. Allantophomopsis lycopodina-a new aerial pathogen of lingonberry (Vaccinium vitis-idaea). Plant Pathol. 54, 248 (2005).

2 Olatinwo, R. O., Hanson, E. J. \& Schilder, A. M. C. A first assessment of the cranberry fruit rot complex in Michigan. Plant Dis. 87, 550-556 (2003).

3 Brachmann, A. O., Forst, S., Furgani, G. M., Fodor, A. \& Bode, H. B. Xenofuranones A and B: phenylpyruvate dimers from Xenorhabdus szentirmaii. J. Nat. Prod. 69, 1830-1832 (2006).

4 Rao, K. V. et al. Butyrolactones from Aspergillus terreus. Chem. Pharm. Bull. 48, 559562 (2000).

5 Nishikawa, M., Tsurumi, Y, Namiki, T., Yoshida, K. \& Okuhara, M. Studies on WF-3681, a novel aldose reductase inhibitor. I. Taxonomy, fermentation, isolation and characterization. J. Antibiot. 40, 1394-1399 (1987).

6 Gottlieb, H. E., Kotlyar, V. \& Nudelman, A. NMR chemical shifts of common laboratory solvents as trace impurities. J. Org. Chem. 62, 7512-7515 (1997).

7 Carris, L. M. Cranberry black rot fungi: Allantophomopsis cytisporea and Allantophomopsis lycopodina. Can. J. Bot. 68, 2283-2291 (1990).

8 Anke, H., Bergendorff, O. \& Sterner, O. Assays of the biological activities of guaiane sesquiterpenoids isolated from the fruit bodies of edible Lactarius species. Food Chem. Toxicol. 27, 393-397 (1989).

9 Schöttler, S., Bascope, M., Sterner, O. \& Anke, T. Isolation and characterization of two verrucarins from Myrothecium roridum. Z. Naturforsch. C. J. Biosci. 61, 309-314 (2006).

10 Weber, W., Anke, T., Steffan, B. \& Steglich, W. Antibiotics from Basidiomycetes. XXXII. Strobilurin E: a new cytostatic and antifungal (E)-beta-methoxyacrylate antibiotic from Crepidotus fulvotomentosus Peck. J. Antibiot. 43, 207-212 (1990).

11 Stärk, A., Anke, T., Mocek, U. \& Steglich, W. Antibiotics from Basidiomycetes. XLII. Omphalone, an antibiotically active benzoquinone derivative from fermentations of Lentinellus omphalodes. Z Naturforsch. C. J. Biosci. 46, 989-992 (1991).

12 Kettering, M., Valdivia, C., Sterner, O., Anke, H. \& Thines, E. Heptemerones A G, seven novel diterpenoids from Coprinus heptemerus: producing organism, fermentation, isolation and biological activities. J. Antibiot. 58, 390-396 (2005).

13 Stadler, M., Mayer, A., Anke, H. \& Sterner, O. Fatty acids and other compounds with nematocidal activity from cultures of Basidiomycetes. Planta Med. 60, 128-132 (1994). 